
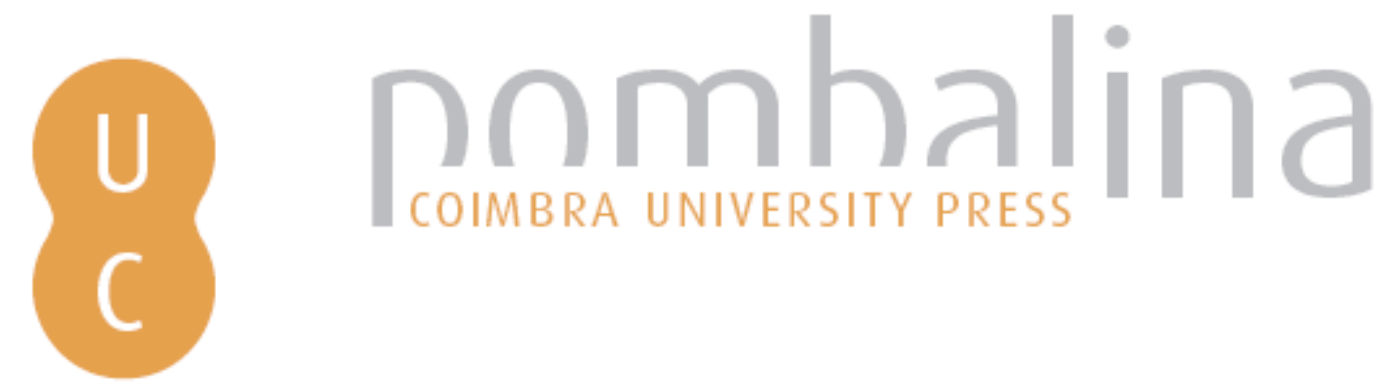

\title{
Parâmetros geomorfológicos para a caracterização de tipologias de terras úmidas
}

Autor(es): $\quad$ Penteado, Adriana de Fátima; Ross, Jurandyr Luciano Sanches

Publicado por: Imprensa da Universidade de Coimbra

URL

persistente:

URI:http://hdl.handle.net/10316.2/31182

DOI:

DOI:http://dx.doi.org/10.14195/978-989-26-0244-8_84

Accessed : $\quad$ 26-Apr-2023 13:48:37

A navegação consulta e descarregamento dos títulos inseridos nas Bibliotecas Digitais UC Digitalis, UC Pombalina e UC Impactum, pressupõem a aceitação plena e sem reservas dos Termos e Condições de Uso destas Bibliotecas Digitais, disponíveis em https://digitalis.uc.pt/pt-pt/termos.

Conforme exposto nos referidos Termos e Condições de Uso, o descarregamento de títulos de acesso restrito requer uma licença válida de autorização devendo o utilizador aceder ao(s) documento(s) a partir de um endereço de IP da instituição detentora da supramencionada licença.

Ao utilizador é apenas permitido o descarregamento para uso pessoal, pelo que o emprego do(s) título(s) descarregado(s) para outro fim, designadamente comercial, carece de autorização do respetivo autor ou editor da obra.

Na medida em que todas as obras da UC Digitalis se encontram protegidas pelo Código do Direito de Autor e Direitos Conexos e demais legislação aplicável, toda a cópia, parcial ou total, deste documento, nos casos em que é legalmente admitida, deverá conter ou fazer-se acompanhar por este aviso. 


\section{TRUNFOS DE UMA}

\section{EOGRAFIA ACIVA}

\section{DESENVOLVIMENTO LOCAL,}

AMBIENTE,

ORDENAMENTO

E TECNOLOGIA

Norberto Santos

Lúcio Cunha

COORDENAÇÃO 
Adriana de Fátima Penteado, Jurandyr Luciano Sanches Ross

Universidade de São Paulo - USP, Faculdade de Filosofia, Letras e Ciências Humanas FFLCH, Departamento de Geografia.

\section{PARÂMETROS GEOMORFOLÓGICOS PARA A CARACTERIZAÇÃO DE TIPOLOGIAS DE TERRAS ÚMIDAS}

\section{INTRODUÇÃO E OBJETIVOS}

As terras úmidas são um dos mais importantes ecossistemas da Terra. Elas servem para a despoluição de águas, amenizam os efeitos das inundaçóes, protegem a linha de praia e recarregam aqüíferos. Além disso, estas áreas têm um importante papel na paisagem por prover um habitat único para uma ampla variedade de vida da flora e da fauna (Mitsch, 1986).

A especificidade e a regionalidade de termos têm prejudicado a identificaçáo correta das terras úmidas que, entre outros problemas, dificulta a comparação entre sistemas similares de diferentes regióes geográficas, pois muitas são as terminologias locais, e nem mesmo em nível nacional ocorre um entendimento.

No Brasil, até o momento não existe um sistema de classificação regional (abrangente) ou mesmo nacional de preservação. As leis que tratam desse assunto geralmente utilizam termos regionais ${ }^{1}$ (pântano, brejo, banhado, alagado, entre outros), que nem sempre incluem todas as classes de terras úmidas de uma região dificultando açóes voltadas para a conservação. $\mathrm{O}$ uso dessas terminologias em trabalhos científicos restringe a compreensáo e dificulta a comparação entre sistemas similares (Maltchik, 2006).

Segundo Giovannini (2003), as legislaçóes brasileiras e gaúchas referentes às terras úmidas encontram-se difusas dentro de Resoluçóes, Portarias, Leis e Decretos, tanto Federais como Estaduais, abrangendo aspectos ligados à proteção ambiental e as águas.

Os dispositivos estaduais para a proteção e gerenciamento das terras úmidas não aparecem de forma direta e clara. Assim, significativas áreas sofrem o risco de desaparecerem, ainda hoje vistas como locais insalubres, de difícil acesso e aproveitamento econômico.

Dessa forma, torna-se importante aprimorar metodologias que auxiliem no melhor entendimento das tipologias das terras úmidas, bem como uma melhor compreensão da dinâmica destas áreas.

\footnotetext{
${ }^{1}$ Pântanos: terreno plano constituindo baixadas inundadas, junto aos rios.

Brejo: terreno plano, encharcado, que aparece nas regióes de cabeceira ou em zonas de transbordamento de rios.

Banhado: Termo derivado do espanhol bañado e usado principalmente no sul do Brasil para as extensôes de terras baixas inundadas pelos rios. Constituem terras boas para culturas, ao contrario dos pântanos. O banhado e um terreno encharcado de água parada que pode, periodicamente, apresentar-se seco.

Alagadiço: terreno sujeito a inundaçóes por parte dos rios ou marés, conforme a sua posição em relação ao mar e rios. Os terrenos alagadiços são encharcados apenas periodicamente e assim durante certo período pode se transformar em área seca.
} 
Dentro desta perspectiva, o objetivo geral desta pesquisa é demonstrar que o mapeamento e a análise geomorfológica podem contribuir para a melhor identificação e caracterização de terras úmidas, diminuindo a lacuna no que se refere ao entendimento das tipologias dessas áreas e, a partir da maior compreensão da dinâmica destas, identificar as principais alteraçóes antrópicas e as suas conseqüências ambientais e sociais.

\subsection{Localização e caracterização geral da área de estudo}

Para a aplicação da proposta de estudo a área escolhida foi a bacia hidrográfica do rio dos Sinos, situada na Região Metropolitana de Porto Alegre - RMPA. Situada a nordeste do estado do Rio Grande do Sul, no sul do Brasil, abrangendo total ou parcialmente 32 municípios com uma área de $3.800 \mathrm{~km}^{2}$, com uma população aproximada de 975.000 habitantes (PROTEGER, 1994).

Segundo Maltchik (2003), recentes pesquisas sobre a biodiversidade biológica das terras úmidas da bacia hidrográfica do rio dos Sinos verificaram uma grande heterogeneidade ambiental desse ecossistema. Nos trechos superior e médio da bacia predominam áreas úmidas de 0.1 a 5 ha. No trecho inferior à medida que o canal do rio começa a se expandir e a declividade se torna praticamente nula, terras úmidas maiores (10 ha) aparecem associadas à planície de inundaçáo, com a formação de sistemas mistos e lagoas.

As terras úmidas da bacia hidrográfica do rio dos Sinos estão sendo destruídas ao longo do tempo, e como conseqüência, a população local sofre com as inundaçóes e com problemas para o suprimento de água potável nos períodos de estiagem.

\subsection{Teórico - Metodológico}

A principal teoria que será utilizada neste trabalho refere-se à proposta metodológica de Aziz Ab Saber (1969), que propóe três níveis básicos de pesquisa em geomorfologia:

Em primeiro nível, deve ser feita a compartimentação da topografia regional, assim como da caracterização e descrição táo exatas quanto possíveis das formas do relevo dos compartimentos estudados.

Em um segundo nível, procurar obter informaçóes sistemáticas sobre a estrutura superficial das paisagens, referentes a todos os compartimentos e formas dos relevos observados.

Em terceiro nível, entender os processos morfoclimáticos e pedogênicos atuais, através da dinâmica climática e de observaçóes mais demoradas e sob controle de equipamentos de precisáo.

A proposta de classificação dos táxons de relevo (Ross, 1992), dá à pesquisa um caminho mais operacional, e tem sua base teórica nos pressupostos de Penck (1953), Guerasimov (1946) e de Mecerjakov (1968), que desenvolveu os conceitos de morfoestrutura e morfoescultura.

\subsection{Operacional}

Por meio das imagens de radar da área de estudo, foi possível extrair curvas de nível que serviram de base para a elaboração dos mapas de declividade e hipsométrico, além da 
elaboração de um Hill Shade que compreende um modelo tridimensional do relevo, auxiliando na elaboraçáo e interpretação de imagens para a geração do mapa geológico. Todos esses mapas juntamente com fotografias áreas e imagens de satélite serviráo como base para a elaboração do mapa geomorfológico, que neste contexto tem por finalidade a identificação e a caracterização de tipologias de terras úmidas, bem como o entendimento da dinâmica das mesmas.

\section{Resultados PRELIMINARES}

\subsection{Aspectos físicos da área de estudo}

A análise de bacias hidrográficas, seja de forma isolada ou integrada, é de grande interesse para a geomorfologia. As paisagens que são modeladas pela erosão fluvial compóem-se de bacias hidrográficas que são unidades de análise adequadas quando se pretende subdividir uma aérea. A evolução de uma paisagem equivale à soma total da evolução de cada uma das bacias individuais de que a paisagem se compóe.

A classificação de terras úmidas, tendo o relevo por parâmetro, pressupóe, a priori, a compartimentaçáo do mesmo, assim considera-se a bacia hidrográfica como uma unidade de análise adequada, pois compreende padróes de formas individualizáveis como morros, colinas e planícies que possuem relaçóes dinâmicas entre si. Esta dinâmica que está inserida nos processos geomorfológicos determina em parte a formação das terras úmidas.

Dessa forma, primeiramente está sendo elaborado o mapa geológico da área de estudo, juntamente com os mapas de declividade e hipsométrico, que irão servir de base para a compartimentação geomorfológica.

O clima da área de estudo, segundo a classificação de W. Koppen é do tipo subtropical, com períodos de clima temperado, meses com temperatura média inferior a $18^{\circ} \mathrm{C}$ e temperatura mínima de cerca de $-3^{\circ} \mathrm{C}$. Clima úmido com precipitação pluviométrica uniformemente distribuída durante todo o ano, com verão muito quente e inverno frio.

Devido às condições climáticas presente no Rio Grande do Sul, predomina o intemperismo químico, este produzindo feições particularizadas sobre o relevo a partir da natureza litológica dos grandes quadros morfoestruturais (Vieira, 1984).

Inserido neste contexto climático, a litologia local, entre outros fatores, define as morfoestruturas onde se insere a área estudada.

A geologia geral da área de estudo é composta por depósitos do quaternário, Formação Serra Geral, Formação Botucatu e Formação Rosário do Sul.

Quanto aos depósitos do quaternário da área de estudo, os sedimentos mais grosseiros localizam-se preferencialmente na cabeceira das drenagens oriundas do escudo sul riograndense e da escarpa basáltica, enquanto que a sedimentação síltico-argilosa desenvolve-se acentuadamente nas extensas planícies de inundação do curso médio e inferior das drenagens principais, locais onde se verificam condiçôes de transbordamento. Sedimentos arenosos constituem também barras de meandros. São nestes depósitos onde se encontram as terras úmidas de maior extensão.

A designação de Formação Serra Geral refere-se à província magmática relacionada aos derrames e intrusivas que recobrem $1,2 \times 10^{6} \mathrm{~km}^{2}$ da Bacia do Paraná, abrangendo toda a região centro-sul do Brasil e estendendo-se ao longo das fronteiras do Paraguai, Uruguai e Argentina. Esta unidade está constituída dominantemente por basaltos e basalto-andesitos de filiaçáo 


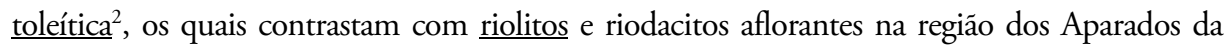
Serra, e que caracterizam uma associação litológica bimodal basalto - riolito (White, 1906).

A Formação Serra Geral, composta basicamente de rochas básicas e ácidas, é intercalada na base com arenitos eólicos. Forma serras escarpadas (transição planalto e depressão) e com cristas com altitude máxima de aproximadamente 980 metros.

O termo Botucatu foi introduzido na literatura geológica para denominar os arenitos que fazem parte da serra de mesmo nome no estado de São Paulo. Esta Formação caracteriza-se pelas estratificaçóes cruzadas, planares ou acanaladas. Além disso, apresenta comumente alternância de lâminas de arenito fino e de arenito médio, o que resulta em bimodalidade textural, Assine, (2004).

Segundo Ramos (1975), os arenitos da Formação Botucatu são predominantemente eólicos de origem, característicos em toda a Bacia do Paraná, compreendendo um dos grandes eventos climáticos ocorridos no Mesozóico.

Quando silicificados, os arenitos mantêm topografia acidentada, com cotas elevadas, constituindo verdadeiras feiçóes de "cuestas" dissecadas, com freqüência "morros testemunhos" nas faces íngremes. Quando friáveis, são facilmente intemperizados, permitindo o modelado de colinas suaves, de vertentes convexas, arredondadas, de média altitude, determinando paisagens onduladas (Ramos, 1975).

A Formação Rosário do Sul aparece em pequena proporção no trecho inferior da bacia formando relevo plano.

\subsection{Urbanização e alterações na dinâmica natural das terras úmidas}

Segundo o PROTEGER (1994), a ocupação urbana ao longo da rede de drenagem superficial tem sido cada vez mais intensa. Na Regiáo Metropolitana de Porto Alegre RMPA, historicamente, as áreas urbanas e eixos de colonização desenvolveram-se a partir dos cursos de água, junto às margens, pois estes eram os caminhos naturais de comunicação entre diferentes regiôes. Assim o padrão da ocupaçáo foi determinado pela hidrografia.

Com o passar do tempo os eixos hidrográficos foram substituídos pelos rodoviários, porém, manteve-se a mesma distribuição espacial de ocupação urbana e circulação. Os eixos rodoviários aceleraram o processo de ocupação de grande contingente populacional, que ocupou principalmente as planícies de inundação dos cursos de água.

No caso especifico das terras úmidas da bacia hidrográfica do rio dos Sinos, um agravante refere-se à localização das mesmas; grande parte em áreas urbanas, na região metropolitana de Porto Alegre, onde se concentra grande parte das indústrias e da populaçáo do estado do Rio Grande do Sul.

A bacia hidrográfica do rio dos Sinos tem sofrido as conseqüências da intensa utilização dos seus recursos hídricos com práticas agropecuárias inadequadas na parte superior e a industrialização e a urbanizaçáo desordenada nas regióes médias e inferiores, enfrentando, entre outros problemas, a escassez de água para o abastecimento de sua comunidade (Cassartelli, 1999).

\footnotetext{
${ }^{2}$ Toleito: variedade de tipo de magma com ampla distribuição na superfície do globo, sendo encontrado em cadeias oceânicas, vulcôes em escudo e regiôes continentais relacionadas à basaltos de platô, como os encontrados na Bacia do Paraná. Fonte: Glossário on line CPRM - Serviço Geológico do Brasil. 16/04/2009.
} 
A urbanização afeta as terras úmidas sensivelmente no nível da paisagem com a diminuição destas por meio do avanço residencial; com a formação de aterros; construção de açudes; mudanças hidrológicas; alteração na qualidade da água; eutrofização; sedimentação; modificações na drenagem e em algumas unidades de um grupo de terras úmidas fechadamente localizadas por meio da fragmentação. Quanto menores as terras úmidas, maiores são as possibilidades de destruição.

Em visitas de campo, ao longo da bacia hidrográfica do rio dos Sinos, foi possível encontrar vários aterros com materiais provenientes de resíduos domésticos e industriais. Em alguns casos a ocupaçáo residencial antecede o processo de aterramento, sendo praticada para amenizar os efeitos das inundaçóes, em outros, as ocupaçóes são uma conseqüência.

Nas terras altas a cultura que predomina é a dos descendentes italianos, com pequenos núcleos de descendentes alemães. Há plantaçóes de verduras e milho, além da agropecuária. Nestas áreas, já é possível verificar sinais de destruição, por meio do desmatamento e da poluição.

Nas terras onduladas a população é formada por alemães e poloneses, num tipo de vida essencialmente rural. As atividades giram em torno da agropecuária, dos arrozais e das pastagens. Nesta área as alteraçóes são bem mais intensas, há muitos desmatamentos, desvios de cursos do rio para irrigaçáo, dragas retirando areia do leito e, a calha do rio já apresenta vestígios de poluição industrial e residencial.

Nas terras baixas, área colonizada por descendentes alemães, mas que conta com uma populaçáo cada vez mais diversificada, ocorre intenso processo erosivo, desmatamento e substituição da vegetação nativa das matas ao longo do rio por eucaliptos. Além disso, intensa poluição do solo, água e terras úmidas. Presença de grande quantidade de lixo industrial e domiciliar na calha do rio e águas com alto grau de contaminação.

\subsubsection{Inundaçóes e a construção dos diques de proteção}

No Rio Grande do Sul o agravamento das cheias periódicas possui relação direta com a diminuição dos ambientes reguladores - as terras úmidas - e com o desmatamento na margem dos rios. $\mathrm{O}$ volume de água da precipitação, que antes ficava retido pela vegetação e era absorvido gradativamente pelos solos antes de chegar aos cursos de água, agora flui rapidamente para os rios, transportando, assim, sedimentos.

No rio dos Sinos as cheias ocorrem principalmente no inverno e têm como causa principal o influxo do lago Guaíba. As cheias deste são provenientes de um conjunto de fatores, entre os quais o de ter um dos maiores índices pluviométricos do Rio Grande do Sul no Planalto Meridional, aliado ao fato de receber praticamente todos os contribuintes da bacia do rio Jacuí. O escudo Sul rio-grandense e o litoral representam um obstáculo ao escoamento das águas até o oceano Atlântico, por isto elas são acumuladas no Guaíba.

A ocupação à margem do rio dos Sinos trouxe aos moradores o problema das inundaçôes, sendo que as mais graves ocorreram em 1941 e 1965.

A solução proposta pelos Engenheiros Consultores da AGRAR UND HYDROTECHNIK, de Essen, Alemanha, para o problema das inundaçóes no trecho inferior da bacia do rio dos Sinos, foi a construção de diques de proteção, conforme constam nos relatórios do Planejamento Hidrológico do Rio dos Sinos de 1969. O projeto de construção dos diques teve início em 1964 e as obras se iniciaram em 1974. 
As obras iniciais de construção dos diques não resolveram efetivamente o problema das inundaçóes. Além disso, estas obras necessitam de constante manutenção para que não haja o seu rompimento. Segundo Tucci (1995), o controle das enchentes urbanas é um processo permanente que deve ser mantido pelas comunidades, visando à redução do custo social e econômico dos impactos.

$\mathrm{Na}$ maioria dos países da Europa, durante a primeira metade do século passado, e mais atualmente no Brasil, muitos rios e córregos foram retificados com o objetivo de proteger zonas urbanas, vias de transporte e terras agrícolas contra cheias. As consideraçóes ambientais náo receberam prioridade. Os maiores prejuízos referem-se à perda da diversidade da biota.

\section{CONSIDERAÇÓES FINAIS}

Dada a grande importância das terras úmidas no que se refere a aspectos ambientais e também sociais, é essencial tomar medidas mais eficazes de proteção dessas áreas. Para a elaboração de uma legislação abrangente e que inclua todas as tipologias dessas áreas, são necessários mais estudos sobre o tema, bem como a definição de metodologias para a caracterização das mesmas.

\section{REFERÊNCIAS BIBLIOGRÁFICAS}

Assine, M. L. \& Piranha, J. M. \& Carneiro, C. D. R. 1994, Os paleodesertos Pirambóia e Botucatu. Capítulo V. Geologia do Continente Sul - Americano. São Paulo.

Ab'sabeR, A. N. 1969, Um conceito de geomorfologia a serviço das pesquisas sobre o quaternário, Geomorfologia $\mathrm{n}^{\circ}$ 18. IGOG - UPS, São Paulo.

BertolucI, V. D. M. 2004, Inventário, Biodiversidade e conservação de área úmidas do município de São Leopoldo, UNISINOS, São Leopoldo.

CasartellI, M. R. O. 1999, Estudo do Fluxo de Metais Pesados na Bacia Hidrográfica do Rio dos Sinos - RS, UNISINOS, São Leopoldo.

Christofoletti, A. 1981, Geomorfologia Fluvial. O canal fluvial, Edgard Blucher, São Paulo.

Christofoletti, A. 1980, Geomorfologia, Edgard Blucher, São Paulo.

Diegues, S. C. 1990, Programa de Pesquisa e Conservaçâo de Áreas Úmidas no Brasil. Inventário de Áreas Úmidas do Brasil, USP/UICN/F. FORD, São Paulo.

Fitz, P. R. 2000, Cartografia Básica, Universidade La Salle, Canoas.

Maltchik, L.\& Rolon, A. S. 2006, Áreas palustres: classificar para proteger, Revista Ciência Hoje. Vol. 38 nº. 228 , São Leopoldo.

Maltchik, L. (Org.). 2003, Biodiversidade e Conservação de Áreas Úmidas da Bacia do Rio dos Sinos, UNISINOS, São Leopoldo.

Maltchik, L. \& Sternet, C. 2003, Áreas úmidas da bacia do rio dos Sinos: diretrizes para programas de conservação, Acta Biológica Leopoldense. Vol. 25 nº. 1, São Leopoldo.

Mitsch, W. J. \& Gosselink, J. G., 1986, Wetlands, Van Nostrand Reinhold, New York.

Giovannini, E. 2003, Características do solo e vegetação, e proposta de método para o delineamento de terras úmidas do Rio Grande do Sul, Universidade Federal do Rio Grande do Sul, Porto Alegre.

Guerra, A. J. T \& Cunha, S. B. 2000, Geomorfologia e Meio Ambiente, Bertrand Brasil, Rio de Janeiro.

Guerra, A. T. 1987, Dicionário Geológico - Geomorfológico, Fundação Instituto Brasileiro de Geografia e Estatística - IBGE, Rio de Janeiro.

Guerasimov, I. P. \& Mecerjakov, J. A. 1968. Morphoestructure. The Encyclopedia of Geomorphology, Reinhold Book, New York.

Projeto PLANAGUA/GTZ de Cooperação Técnica Brasil - Alemanha. 1998, Rios e Córregos. Preservar Conservar - Renaturalizar a recuperação de rios. Possibilidades e Limites da Engenharia Ambiental, Sáo Leopoldo. 
Projeto RADAMBRASIL. 1986, Folha SH 22. Porto Alegre e parte das folhas SH 21 Uruguaiana e SI 22 Lagoa Mirim, IBGE, Rio de Janeiro.

PROTEGER - Programa Técnico para o Gerenciamento da Regiāo Metropolitana de Porto Alegre. 1994, Áreas de inundação, Alagamento e Banhados, Metroplam, CPRM - Serviço Geológico do Brasil, Porto Alegre.

Ramos, E. M. 1975, Aspectos Geográficos e Geológicos da Regiäo Metropolitana de Porto Alegre (Norte), UFRGS, Porto Alegre.

Ross, J. L. S. 1994, Geomorfologia: ambiente e planejamento, Contexto, São Paulo.

Tiner, RW. 1999, Wetland indicators, Lewis, New York.

Tucci, C. E. M. \& Porto, R. L. L. \& Barros, M. T. de (Orgs.). 1995, Drenagem Urbana, ABRH - Associação Brasileira de Recursos Hídricos, Porto Alegre.

White, I.C. 1906, Relatório Final da Comissão de Estudos das Minas de Carvão de Pedra do Brasil, DNPM, Rio de Janeiro.

Vieira, E. F. 1984, Rio Grande do Sul Geografia Física e Vegetação, Sagra, Porto Alegre. 